\title{
Electrochemical, DFT and Mont Carlo Simulations Studies to Evaluate the Inhibition Effect of Novel Pyridazine Derivatives on Iron Pitting Corrosion in 3.5 \% NaCl
}

\author{
M. M. El-Deeb ${ }^{1,2, *}$, N. S. Abdel-Shafi ${ }^{1,3}$ and A. H. Shamroukh ${ }^{1,4}$ \\ ${ }^{1}$ Chemistry Department, Faculty of Science, Ha'il University, 81451 Hail, P.O. Box 2440, KSA \\ ${ }^{2}$ Chemistry Department, Faculty of Science, Beni-Suef University, 62511, Beni-Suef, Egypt. \\ ${ }^{3}$ Chemistry Department, Faculty of Education, Ain Shams University, Roxy, Cairo, Egypt \\ ${ }^{4}$ Photochemistry Department, National Research Centre, Dokki, 12622 Giza, Egypt \\ *E-mail: eldeebm@yahoo.com
}

doi: $10.20964 / 2018.06 .70$

Received: 8 February 2018 / Accepted: 12 April 2018 / Published: 10 May 2018

(6-Phenyl-pyridazin-3-ylsulfanyl)-acetic acid ethyl ester (PPS-A) and 4-(6-Phenyl-pyridazin3-ylsulfanyl)-butyric acid ethyl ester (PPS-B) are synthesized and characterized as novel $S$-alkylated pyridazine derivatives with different side chain lengths. The effect of $S$-alkylated side chain lengths in PPS-A and PPS-B is investigated for their protective mechanism towards iron pitting corrosion in 3.5 $\% \mathrm{NaCl}$ and compared to their parent pyridazine (PPS) using electrochemical measurements and theoretical calculations. It is found that, the studied pyridazine derivatives shift both the corrosion potential and the pitting potential of iron to more noble values. Furthermore, the mechanism of the inhibition is correlated to the presence of the $S$-alkylated side chain in PPS-A and PPS-B compared to PPS, as well as to its different lengths between PPS-A and PPS-B. Moreover, the structure of Fe/electrolyte interface in case of PPS-B behaves as more ideal capacitive rather than that in case of PPS-A, due to the adsorption of insulating barrier layers on Fe/electrolyte interface. The best fit adsorption isotherm is found to be Langmuir adsorption isotherm with physical nature. DFT calculations show that, the charge density around the adsorption active sites increase as the $S$-alkylated side chain became more length. The adsorption behaviour of the studied pyridazine derivatives is simulated using Mont Carlo molecular dynamics that agree well with the experimental data.

Keywords: Pyridazine derivatives, Iron, Pitting corrosion, EIS, Mont Carlo simulations

\section{FULL TEXT}

(C) 2018 The Authors. Published by ESG (www.electrochemsci.org). This article is an open access article distributed under the terms and conditions of the Creative Commons Attribution license (http://creativecommons.org/licenses/by/4.0/). 